\title{
Simulasi Kekuatan Mekanik Sudu Turbin Angin Horizontal Menggunakan Software Simscale
}

\author{
Mubni Nazar ${ }^{1}$, Anggito P. Tetuko ${ }^{2}$, dan Djuhana ${ }^{1}$ \\ ${ }^{1}$ Program Studi Teknik Mesin, Universitas Pamulang, Jl. Surya Kencana No.1, Pamulang 15417, \\ Tangerang Selatan, Indonesia. \\ ${ }^{2}$ Pusat Penelitian Fisika, Lembaga Ilmu Pengetahuan Indonesia, Serpong 15314, Tangerang Selatan, \\ Indonesia. \\ E-mail: mubninazar12@gmail.com
}

Masuk :28 Oktober 2020

Direvisi :1 November 2020

Disetujui :2 januari 2021

\begin{abstract}
Abstrak: Penelitian ini dilakukan untuk meningkatkan koefisien daya yang maksimal. Salah satunya dengan mengunakan kualitas sudu yang baik. Untuk mengoptimalkan fungsi turbin angin penulis menggunakan material sudu pada turbin angin dengan menggunakan Acrylonitrine Butadine Styrene (ABS). Oleh karena itu pada penelitian ini metode yang digunakan adalah metode Finite Element Analysis Simulasi yang dipilih adalah dynamic. Penelitian ini adalah pengujian kekuatan sudu turbin angin horizontal dengan variasi kecepatan angin $10-20 \mathrm{~m} / \mathrm{s}$ ditinjau dari von mises stress dan displacement. Dari hasil simulasi kecepatan angin memiiki pengaruh terhadap distribusi stress dan displacement. Material yang digunakan masih berada di bawah batas kekuatan material, semakin besar gaya yang diberikan semakin besar nilai stress dan displacement. Pada hasil simulasi didapatkan nilai stress minimum $5.8 \mathrm{~Pa}$ stress maksimum 22.94 Sedangkan dalam pengujian displacement dihasilkan nilai minimum $1.27 \mathrm{~m}$ displacement maksimum $4.99 \mathrm{~m}$.
\end{abstract}

Kata kunci: Turbin Angin Horizontal, ABS, Von Mises Stress, Displacement.

Abstract: This research was conducted to increase the maximum power coefficient. One of them is by using a good quality blade. To optimize the function of the wind turbine, the authors use the blade material in the wind turbine using Acrylonitrine Butadine Styrene (ABS). Therefore, in this study the method used is the Finite Element Analysis method. The simulation chosen is dynamic. This research is a test of horizontal wind turbine blade strength with wind speed variations of $10-20 \mathrm{~m} / \mathrm{sec}$ in terms of stress and displacement. From the simulation results, wind speed has an influence on the distribution of stress and displacement. The material used is still below the material strength limit, the greater the force applied, the greater the stress and displacement values. In the simulation results, the minimum stress value is 5.8, the maximum voltage $\mathrm{Pa}$ is 22.94, while in the displacement test the resulting value is $1.27 \mathrm{~m}$, the maximum displacement is 4.99 $m$.

Keywords: Horizontal Wind Turbine, ABS, Von Mises Stress, Displacement

\section{PENDAHULUAN}

Energi angin adalah energi alternatif yang merupakan sumber energi yang terbarukan. Angin adalah udara yang bergerak diakibatkan oleh rotasi bumi dan juga adanya perbedaan tekanan udara disekitarnya. Angin bergerak dari tempat bertekanan udara tinggi ke bertekanan rendah [1].

Turbin angin merupakan suatu alat yang mampu mengubah energi angin menjadi energi mekanik dan selanjutnya diubah menjadi energi listrik melalui generator. Turbin angin poros horizontal ini dapat ditingkatkan efisiensinya untuk mendapat koefisien daya yang maksimal. Salah satunya dengan mengunakan kualitas sudu yang baik [2].

Produk yang baik sangat bepengaruh terhadap kelangsungan hidup suatu perusahaan, contoh produksi sudu turbin angin horizontal, sudu trbin angin horizontal adalah suatu komponen dalam turbin angin yang digunakan untuk menerima energi kinetik dari angin dan merubahnya menjadi energi mekanik. Dalam proses pembuatan 
sudu turbin angin horizontal tidak akan terlepas dari cacat proses produksi hal ini sangat merugikan bagi perusahaan. Banyak faktor yang mempengaruhi tingkat kegagalan dalam proses produksi, Antara lain faktor material yang digunakan untuk membuat sudu turbin angin horizontal.

Oleh karena itu penelitin ini bertujuan untuk mempelajari kekutan mekanik sudu turbin angin dengan pengaruh kecepatan angin terhadap distribusi stress dan displacement pada sudu. Dengan menggunakan material Acrylonitrine Butadine Styrene (ABS) diharapkan sudu turbin mendapatakan kualitas terbaik dari sifat mekaniknya.

\section{METODOLOGI}

Model 3D dibuat dengan menggunakan software autoCAD. Simulasi dilakukan dengan model 3D pada (Gambar 1). Penelitian ini dilakukan dengan metode simulasi numerik dengn bantuan perangkat lunak SIMSCALE berbasis Finite Element Method yaitu salah satu dari metode numerik yang memanfaatkan operasi matrix untuk menyelesaikan masalah-masalah fisik. Metode ini dikenal sebagi metode elemen hingga, karena kita membagi permasalahan menjadi sejumlah elemen tertentu (finite) untuk mewakili permasalah yang sebenarnya jumlah elemennya adalah tidak berhingga [3].

Material yang digunakan dalam pembuatan sudu turbin angin ini Acrylonitrine Butadine Styrene (ABS) yaitu sejenis kopolimer termoplastik yang tersusun dari polimer-polimer lainnya [4].

Tabel 1. Sifat Mekanik plastik ABS

\begin{tabular}{|c|c|}
\hline Modulus Young & $2.62 \mathrm{GPa}$ \\
\hline Density & $1030\left(\mathrm{~kg} / \mathrm{m}^{3}\right)$ \\
\hline Poisons Ratio & 0.34 \\
\hline $\begin{array}{c}\text { Ultimate Tensile } \\
\text { Strength }\end{array}$ & $71.5 \mathrm{MPa}$ \\
\hline
\end{tabular}

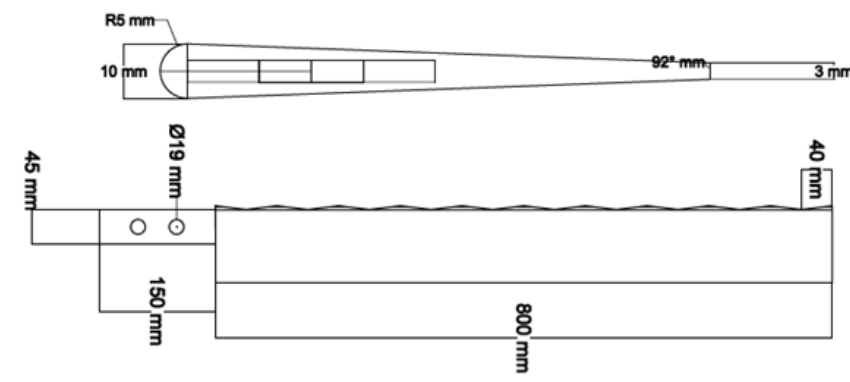

Gambar 1. Desain turbin angin horizontal

\section{Nilai asumsi}

Sebelum melakukan analisis lebih lanjut terlebih dahulu menentukan nilai asumsi untuk penelitian sebagai berikut: [5]

Kecepatan angin $10-20 \mathrm{~m} / \mathrm{s}$.

Koefisien kerja (Cp) 0.3

Efisiensi listrik dan mekanik 0,95 dan 0,90.

Untuk luas (A) akan mengikuti desain sudu.

Density udara $\left(1.225 \mathrm{~kg} / \mathrm{m}^{3}\right)[5]$

Untuk memperoleh nilai gaya (force) maka dilakukan perhitungan berikut [6] 


\section{Daya Angin \\ $\mathrm{P}_{\mathrm{w}}=\frac{1}{2} \rho \mathrm{Av}^{3} C p \eta e \eta m$}

\section{Dimana:}

$$
\begin{array}{ll}
P_{w} & =\text { Daya angin (watt) } \\
\rho & =\text { Massa jenis udara } \\
& \left(\rho=1.225 \mathrm{~kg} / \mathrm{m}^{3}\right) \\
A & =\text { Luas penampang turbin }\left(\mathrm{m}^{2}\right) \\
v & =\text { Kecepatan angin }(\mathrm{m} / \mathrm{s})
\end{array}
$$

\section{Tip Speed Ratio (TSR)}

$$
\mathrm{n}=\frac{60}{\pi} \frac{\mathrm{v}}{2 \mathrm{r}}
$$

Dimana :

$$
\begin{array}{ll}
\mathrm{n} & \text { : tip speed ratio } \\
\mathrm{r} & : \text { jari-jari sudu }(\mathrm{m}) \\
\mathrm{v} & : \text { keepatan ang in }(\mathrm{m} / \mathrm{s})
\end{array}
$$

3. Torsi

$\mathrm{T}=9.55 \times 10^{6} \frac{\mathrm{P}}{\mathrm{n}}$

Dimana :

T : Torsi (N.mm)

P : Daya (W)

n : kecepatan rotasi (RPM)

Berdasarkan pada perhitungan diatas dapat diperoleh nilai gaya berikut

Tabel 2. Hasil perhitungan nilai gaya [5]

\begin{tabular}{cccccc}
\hline No & $\mathrm{v}(\mathrm{m} / \mathrm{s})$ & $\mathrm{P}(\mathrm{W})$ & $\mathrm{n}(\mathrm{RPM})$ & $\begin{array}{c}\mathrm{T} \\
(\mathrm{N} . \mathrm{mm})\end{array}$ & $\mathrm{F}(\mathrm{N})$ \\
\hline 1 & 10 & 11.94 & 239 & 477 & 1.2 \\
2 & 11 & 15.89 & 264 & 577 & 1.4 \\
3 & 12 & 20.63 & 287 & 688 & 1.7 \\
4 & 13 & 26.23 & 310 & 808 & 2 \\
5 & 14 & 32.76 & 334 & 936 & 2.3 \\
6 & 15 & 40.29 & 358 & 1074 & 2.6 \\
7 & 16 & 48.90 & 382 & 1222 & 3 \\
8 & 17 & 58.66 & 406 & 1379 & 3.4 \\
\hline
\end{tabular}

Dari hasil perhitungan nilai gaya yang akan digunakan dalam proses pemasukan data dalam proses simulasi dalam force digunakan untuk mendapatakn nilai tegangan stress dan displacement. 


\section{HASIL DAN DISKUSI}

Dari hasil pengujian didapatakn hasil simulasi distrubusi tegangan stress dan displacement menggunakan software simscale
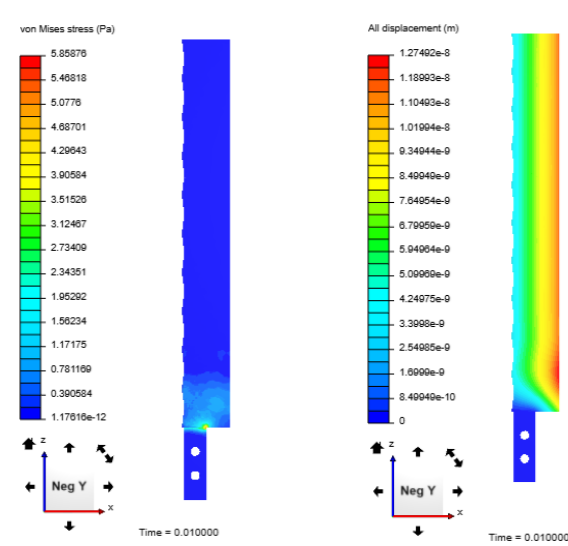

Gambar 2. Simulasi kecepatan angin $10 \mathrm{~m} / \mathrm{s}$.
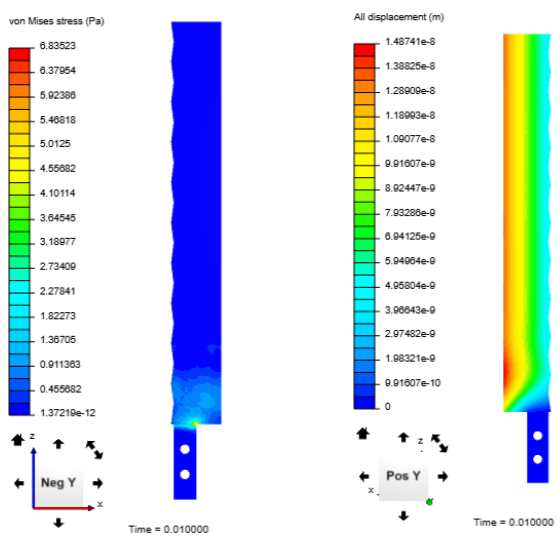

Gambar 3. Simulasi kecepatan angin $11 \mathrm{~m} / \mathrm{s}$.
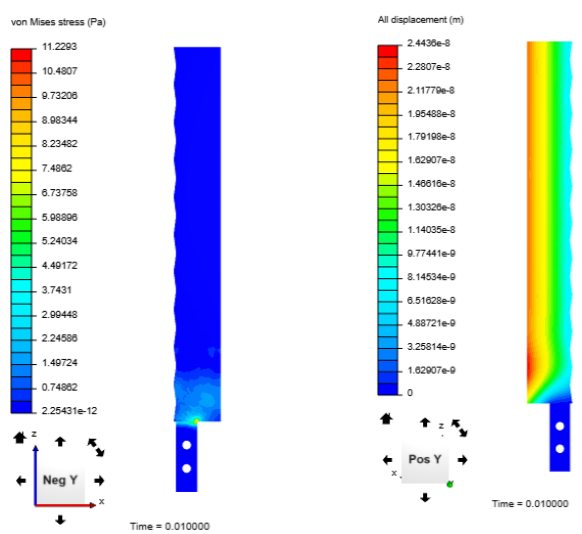

Gambar 6. Simulasi kecepatan angin $14 \mathrm{~m} / \mathrm{s}$.
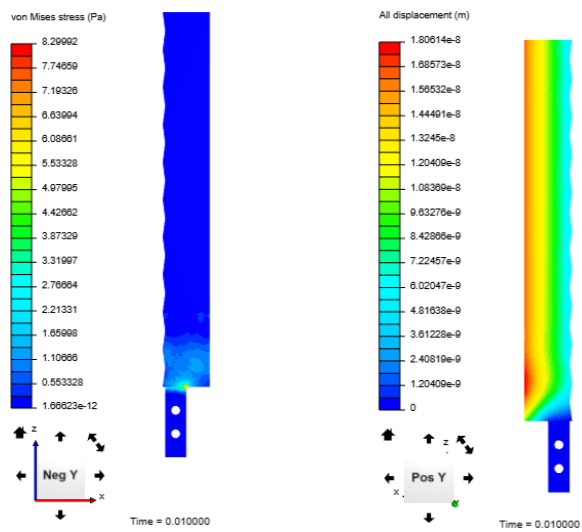

Gambar 4. Simulasi kecepatan angin $12 \mathrm{~m} / \mathrm{s}$.
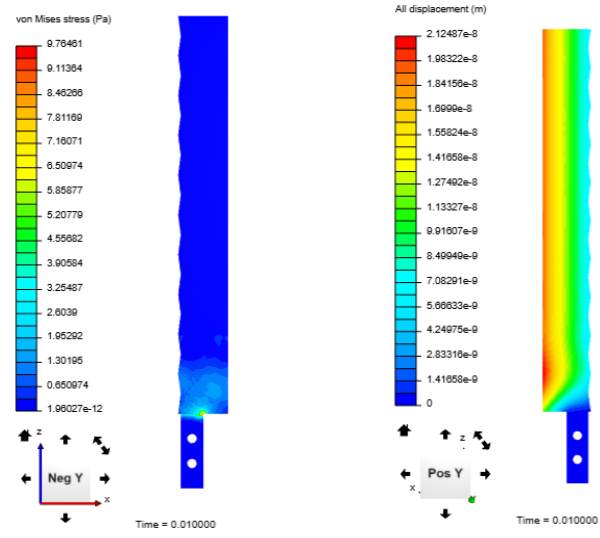

Gambar 5. Simulasi kecepatan angin $13 \mathrm{~m} / \mathrm{s}$.
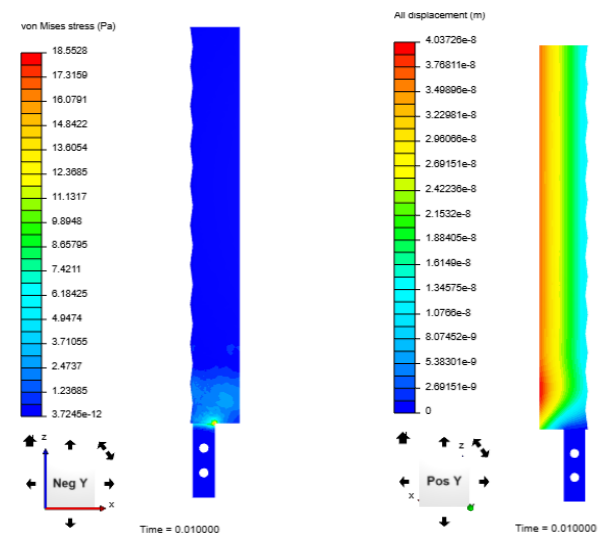

Gambar 10. Simulasi kecepatan angin $18 \mathrm{~m} / \mathrm{s}$. 

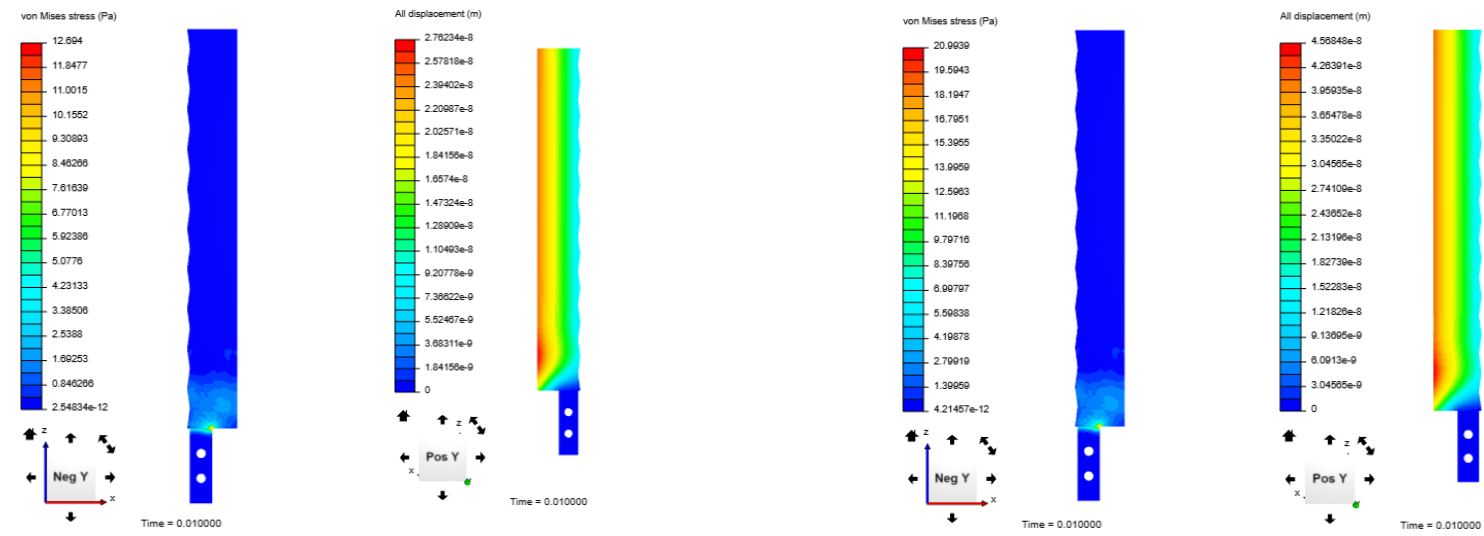

Gambar 7. Simulasi kecepatan angin $15 \mathrm{~m} / \mathrm{s}$.

Gambar 11. Simulasi kecepatan angin 19 m/s.
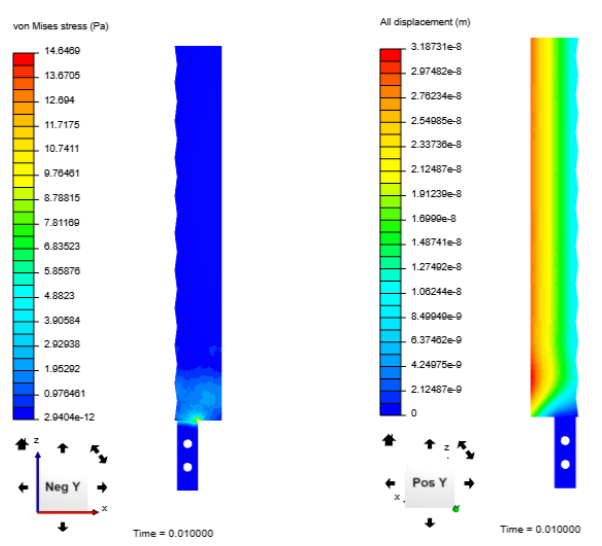

Gambar 8. Simulasi kecepatan angin $16 \mathrm{~m} / \mathrm{s}$.
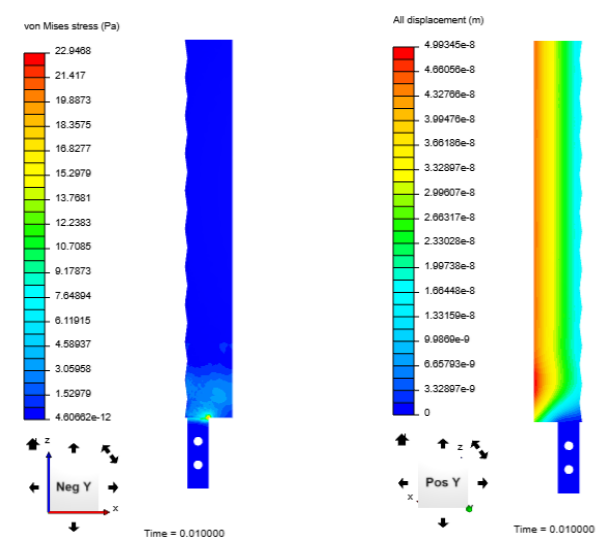

Gambar 12. Simulasi kecepatan angin $20 \mathrm{~m} / \mathrm{s}$.

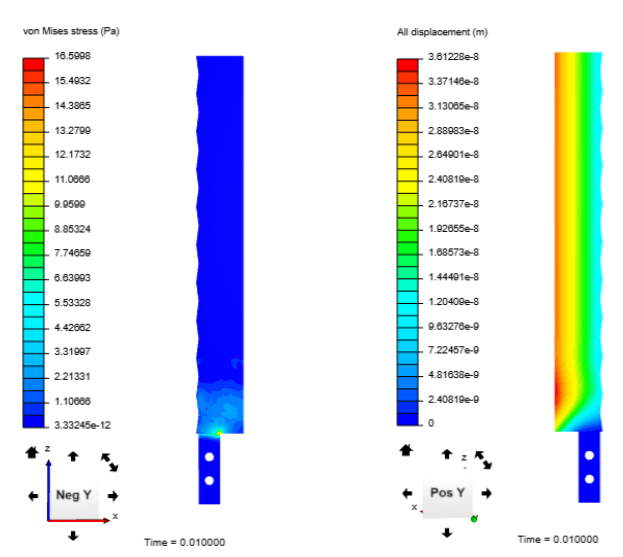

Gambar 9. Simulasi kecepatan angin $17 \mathrm{~m} / \mathrm{s}$.

Hasil diperoleh untuk satu bilah sudu turbin angin sudu horizontal dengan 10 gerigi. Dengan kecepatan yang berbeda mempengaruhi nilai tegangan stress dan displacement. Disetiap kecepatan angin denga nilai gaya yang berbeda didapatkan nilai minimum sampai dengan nilai maksimum. Dalam hasil simulasi ditunjukan dengan menggunakan kotur warna yang diartikan dalam setiap warna menunjukan kenaikan tingkat stress pada 
area warna biru tua yaitu area yang memiliki tingkat stress paling rendah kemudian warna biru muda hijau dan kuning berada tingkat stress sedang hingga warna merah dengan tingkat stress paling tinggi.

Dari hasil yang di dapatkan diketahui bahwa tegangan stress maksimum terjadi secara umum pada daerah penyambung antara sudu dan pegangan rotor. Stress yang di alami pada bagian depan dan belakang berbeda pada bagian belakang tingkat stress lebih besar dapat dilihat pada penyebaran warna merah lebih banyak. Sedangkan displacement terjadi secara umum pada daerah samping sudu yang memiliki dimensi lebih kecil atau tipis, sedangkan nilai displacement maksimum terjadi pada daerah samping bagian bawah sudu yang memiliki penyebaran warna merah lebih banyak.

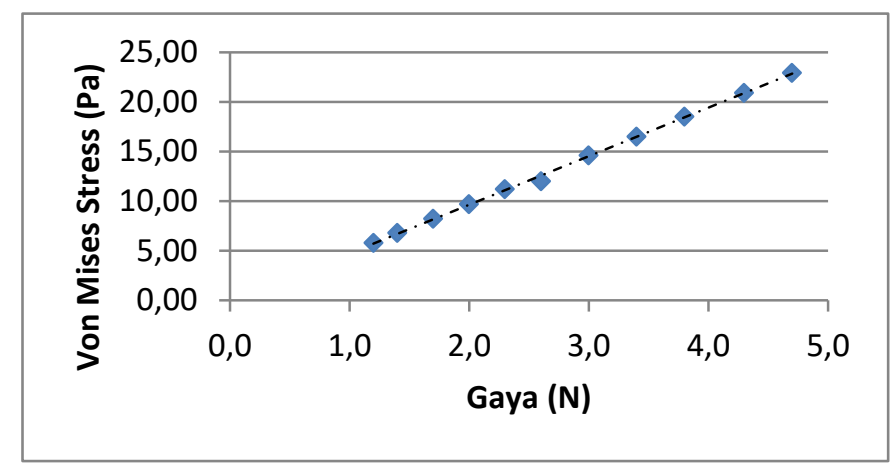

Gambar 13. Nilai stress maksimum

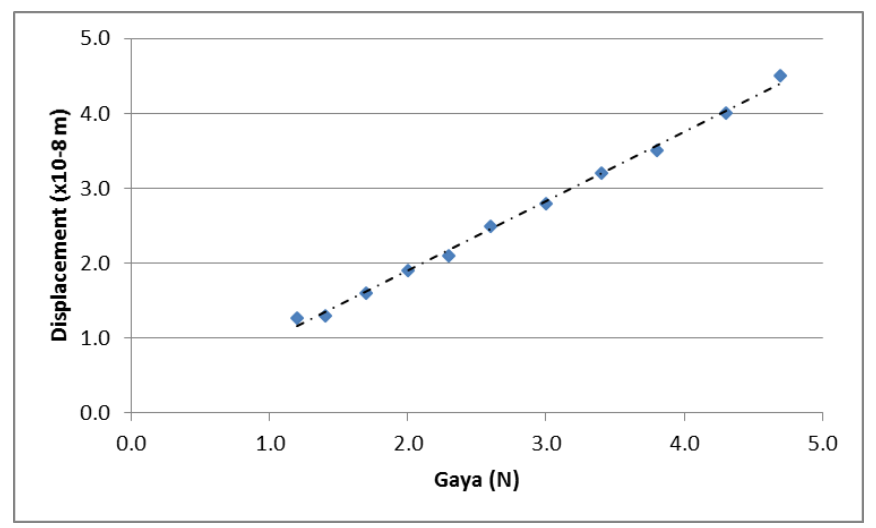

Gambar 14. Nilai displacement maksimum

Berdasarkan gambar 13 dan 14 sudu turbin angin horizontal dengan material Acrylonitrile Butadiene Styrene (ABS) mengalami tingkat stress yang berbeda dengan pembebanan gaya 1.2, 1.4, 1.7, 2, 2.3, 2.6, 3, 3.4, 3.8, 4.3, 4.7 N. Semakin besar gaya yang diberikan maka stress semakin besar, dalam pengujian dihasilkan tingkat stress minimum pada gaya $1.2 \mathrm{~N}$ dengan nilai $5.8 \mathrm{~Pa}$ sedangkan nilai stress maksimum pada pembebanan gaya $4.7 \mathrm{~N}$ dengan nilai $22.94 \mathrm{~Pa}$. Sedangkan dalam pengujian displacement dihasilkan nilai minimum pada gaya $1.2 \mathrm{~N}$ dengan nilai $1.27 \mathrm{~m}$ sedangkan nilai displacement maksimum pada pembebanan gaya $4.7 \mathrm{~N}$ dengan nilai $4.99 \mathrm{~m}$.

\section{KESIMPULAN}

Dari hasil pengujian kecepatan angin $10-20 \mathrm{~m} / \mathrm{s}$. Nila rata-rata setiap kenaikan gaya dari $10-20 \mathrm{~m} / \mathrm{s}$ yaitu 3.04 Pengaruh von mises stress semakin besar kecepatan angin yang dihasilkan semakin besar dan sebaliknya nilai von mises stress kecil jika kecepatan angin kecil. Pada gaya $1.2 \mathrm{~N}$ nilai stress maksimum 5.8 $\mathrm{Pa}$, pada gaya $4.7 \mathrm{~N}$ hasil stress maksimum 22.94. Sama halnya seperti hasil von mises stress, nilai displacement semakin besar jika nilai kecepatan angin semakin besar. Pada gaya $1.2 \mathrm{~N}$ nilai displacement $1.27 \mathrm{~m}$, pada gaya $4.7 \mathrm{~N}$ hasil displacement $4.99 \mathrm{~m}$. Dari data yang di diperoleh dapat dilihat pada sifat mekanik ABS masih dibawah batas aman untuk digunakan. 
70 | Mubni Nazar, dkk., Simulasi Kekuatan Mekanik Sudu Turbin Angin ....,

\section{UCAPAN TERIMA KASIH}

Penulis mengucapkan terima kasih kepada Program Studi Teknik Mesin-Universitas Pamulang dan Pusat Penelitian Fisika-Lembaga Ilmu Pengetahuan Indonesia atas dukungan dalam penelitian ini.

\section{DAFTAR PUSTAKA}

[1] B. Tjasyono, "Meteorologi Indonesia Volume I", Jakarta: Badan Meteorologi Klimatologi dan Geofisika, 2012.

[2] Y. Daryanto, "Kajian Potensi angin Untuk Pembangkit Listrik Tenaga Bayu," Bala PPTAGG-UPT-LAGG, April, 2007.

[3] Akin, J. E., "Finite Elements for Analysis and Design". San Diego: Academic Press, 1994.

[4] Acrylonitrile butadine styrene, January 18, 2011.

[5] G. Y. Huang, Y. C. Shiah, C. J. Bai, and W. T. Chong, "Experimental study of the protuberance effect on the blade performance of a small horizontal axis wind turbine," J. Wind Eng. Ind. Aerodyn., vol. 147, pp. 202-211, 2015.

[6] P. Gipe, "Wind power renewable energy for home farm and business", Chelsia Green Publication Company, White River Junction, VT, Page no. 61, 2004 